\title{
Twitter and weather services
}

\author{
Santiago Gaztelumendi ${ }^{1,2}$, Maialen Martija ${ }^{1,2}$, and Olatz Principe ${ }^{1,2}$ \\ ${ }^{1}$ Basque Meteorology Agency (EUSKALMET), Vitoria-Gasteiz, Basque Country, Spain \\ ${ }^{2}$ Meteorology Area, Energy and Environment Division, \\ TECNALIA R \& I, Vitoria-Gasteiz, Basque Country, Spain \\ Correspondence: Santiago Gaztelumendi (santiago.gaztelumendi@tecnalia.com)
}

Received: 15 February 2018 - Revised: 28 July 2018 - Accepted: 17 August 2018 - Published: 11 September 2018

\begin{abstract}
This work focuses on the analysis of the use of Twitter by different weather services around the world. During the last few years the availability of mobile phones connected to the Internet has become a global reality. Likewise, the use of different social networks has been popularized and extended with different purposes including social communication. In this context most meteorological weather services have been using some of these social tools in order to improve their services for the general public and specific users. Twitter is a social tool that enables users to post messages ("tweets") of up to 280 characters (up to 140 before November 2017), supporting a wide variety of communicative practices. Twitter is an opportunity not only to spread messages without intermediaries, but also interact in real time with users. Here we present a study of different aspects related to the use of Twitter in diverse weather services worldwide and their evolution during the year 2016.
\end{abstract}

\section{Introduction}

Weather Services (WS) use different "traditional" tools for meteorological information dissemination, including television, radio, newspaper, phone, e-mail and public/private websites. In recent years, new technologies, and in particular the rapid expansion of social networks, have allowed the transmission of information to be virtually instantaneous and accessible to large segments of population. As a consequence many National WS have developed new communication strategies and incorporated social network tools (YouTube, Facebook, Instagram, Twitter, etc.) for various purposes (Gaztelumendi et al., 2015; Palacio et al., 2014, 2016; Martija et al., 2014). Particularly, some WS utilize Twitter for quick and efficient communication with their audiences, providing frequent remarkable pieces of information routinely including forecast, observations, analysis, etc. (Gaztelumendi et al., 2015).

With more than 300 million monthly active users, more than 100 million users logging in and 500 million tweets sent daily, Twitter is the 5th most popular social media platform in the world (Smart Insights, 2018). Twitter has many addons that make it powerful, although the standard remains in 280 character text messages (Tsukayama, 2017) and the ability to provide others with frequent information updates and attached extra information (photos, charts, maps, pdf, etc.). In general, National WS use Twitter for fast and efficient communication with users, including different kind of information such as routine weather forecasts and observations, general weather, climate and scientific information, events communications and others (Gaztelumendi et al., 2015). In many cases, this platform is also used for real time severe weather data dissemination and warnings (Orbe, 2012; Gaztelumendi et al., 2012, 2013, 2015, 2016).

\section{Methodology}

Based on previously available work (Gaztelumendi et al., 2015; Palacio et al., 2014) and on official World Meteorological Organization information about official WS (WMO, 2017) we have identified the Twitter accounts of different WS operating at national and local levels around the world. During 2016, when the maximum number of characters was 140 , we completed daily routine queries through the Twitter search Application Programming Interface (API) and Twitter website in order to collect tweets sent from the most representative WS Twitter accounts. Operational scripts to acquire information for this work are programmed in $\mathrm{R}$ 


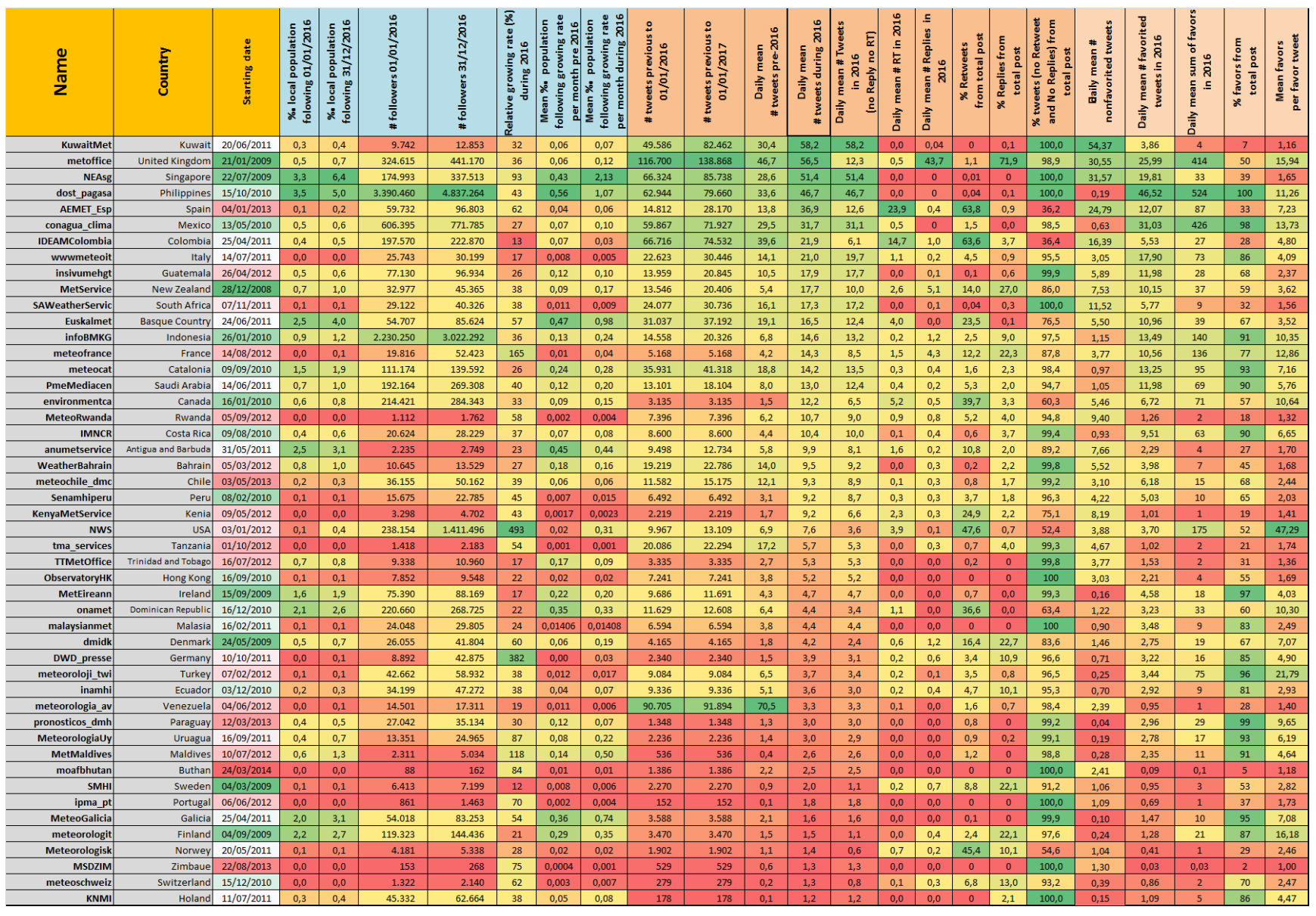

Figure 1. Summary of some metrics and statistics for followers and tweets considering different aspects about the weather services included in this study. Ordered by mean daily number (\#) of messages posted (tweets) during 2016. Cell colors from high values in green to low values in red.

( $\mathrm{R}$ core Team, 2014) with extensive use of twitteR package (Gentry, 2016). All the information (text, time, retweets, replies, followers, favorites, etc.) was stored in daily plain text files for each account (more than 17520 files with more than 314000 tweets). Other R (Sanchez, 2013) and Excel tools were used for debug, data analysis, text mining, graphs and reporting.

\section{Results and discussion}

\subsection{Total tweets}

A tweet is a message (also called a post or an update) distributed on Twitter. The mean number of tweets (for all WS included in the study) per day previous to 2016 was 10.8. During 2016 a general increase to 12.7 was observed, except for the Venezuela or Tanzania case, which showed a significant decrease. KuwaitMet (Kuwait), metoffice (UK), NEAsg (Singapore), dost_pagasa (Philippines), AEMET_Esp (Spain) and conagua_clima (Mexico) posted more than 10000 tweets during 2016, an average daily update rate up to 30 tweets (see Fig. 1).

The daily post update was very different depending on WS. In the case of the most active WS - KuwaitMet (Kuwait), 58 tweets daily - tweets were mainly automatic posts with current weather information including temperature, wind and precipitation data from different automatic stations. On the other hand the metoffice (UK), with 56 daily tweets on average, posted 43 tweets with replies to specific users promoting direct communication with followers. In the case of NEAsg (Singapore) the daily ratio of 51 tweets mainly consisted of automatic Poiutant Standar Index (PSI) real time information. Dost_pagasa (Philippines) (46 tweets per day) posted weather forecast, thunderstorm information and surveillance information in a formal way. AEMET_Esp (Spain) (36 tweets per day) disseminated weather information, warnings, observation, general information and curiosities. Conagua_clima (Mexico) had 31 tweets per day on average, posting different types of weather forecasts (general, regional, short term, etc.), severe weather warnings, obser- 


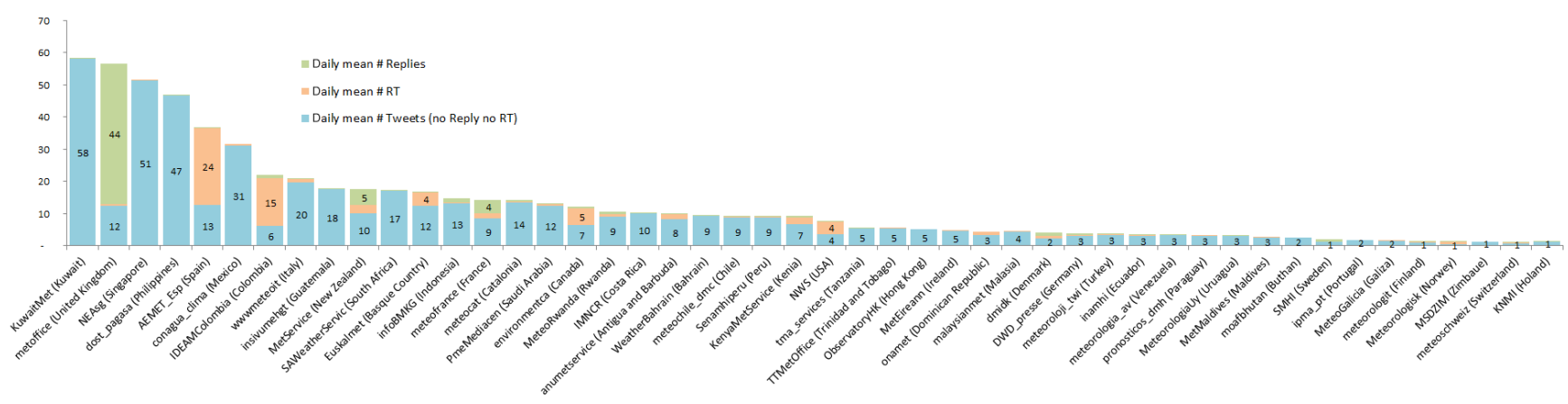

Figure 2. Average daily number (\#) of tweets posted by different WS including the proportion of Retweets (RT) and Replies.

vations, curiosities, and educational content in ordinary language.

\subsection{Retweets (RT)}

A retweet is the way someone can forward another user's tweet to their followers. There are two options: the Twitter Retweet (without adding your own comments), or tweeting with RT (including the option to add your comments) (Boyd et al., 2010). $70 \%$ of the studied counts have a proportion of retweets less than $10 \%$ of the total posts. Six of the WS never retweeted. In the opposite, with more than $60 \%$ of retweets, AEMET_Esp (Spain) had 24 retweets daily on average; IDEAMColombia (Colombia) with 14 corresponding to $63 \%$ of total; and NWS (USA) with $47 \%$ of retweets (see Figs. 1 and 2).

In the AEMET_Esp (Spain) case, retweets came from other AEMET accounts (regional and SINOBAS) and other followers that share weather related comments in some cases with attached photos and videos. In the case of IDEAMColombia (Colombia), retweets were in a large proportion from other institutions and new accounts, and in lesser proportion from particular users that shared photos and weather related comments. NWS (USA) retweeted posts from other NWS accounts, NOAA and other USA institutions with weather and environment general information.

Only 127 tweets posted by studied WS were retweeted more than one thousand times. 103 were retweets from other sources with general information, environmental curiosities and climate information. Only 24 cases were selfproduced content, mainly due to early warnings in the case of infoBMKG (Indonesia), and some general information in the case of metoffice (UK). The top five with more than 100000 retweets count were PmeMediacen (Saudi Arabia), retweeting general messages from the Royal Family (@KingSalman, @M_Naif_Alsaud).

\subsection{Replies}

A reply is a response to something written by someone (a post) on Twitter. Two options are possible: an @ reply or direct message reply (DM). More than $75 \%$ of WS had a proportion of replies of less than $5 \%$ and 13 of them never reply. In the opposite were metoffice (UK), MetService (New Zealand), dmidk (Denmark), meteofrance (France), SMHI (Sweden), meteorologit (Finland) and meteoschweiz (Switzerland), where more than $20 \%$ of total tweets were replies. At the top the metoffice (UK), with a proportion of $72 \%$ of public replies to users, corresponding to 43.7 daily replies on average during 2016 (see Figs. 1 and 2).

Metoffice (UK) replies (more than $70 \%$ tweets posted) consist of direct brief conversations with users solving forecast doubts, giving them direct information about weather conditions on particular locations, or congratulations for shared pictures. In the case of MetService (New Zealand) ( $27 \%$ of total tweets were replies) dealt with local forecast clarification, appreciation for sharing photos, and solving general weather related curiosities in direct and commonplace language.

\subsection{Favorited}

Although the sense and real significance of favoriting a tweet is unclear, in this context we consider it as a kind of "like" in the sense of approval or agreement with particular content. The number of times a WS tweet is favorited is around five on average, but ranges from 47 from NWS (USA) and 20 from meteoroloji_twi (Turkey), to less than one in the case of 23 WS postings. Dost_pagasa (Philippines), conagua_clima (Mexico) and metoffice (UK) had more than 200000 favorites during 2016. Dost_pagasa (Philippines), conagua_clima (Mexico) and metoffice (UK) had more than 400 favorites per day. NWS (USA) had the highest ratio of favorites per tweet (47), but only for $52 \%$ of total favorited tweets (see Figs. 1 and 3). Only 22 tweets were favorited more than 600 times, from meteoroloji_twi (Turkey) (three times), environmentca (Canada) (one time), metoffice (UK) (nine times), NWS (USA) (three times), IDEAM_Colombia (Colombia) (one time), conagua_clima (Mexico) (one time) and infoBMKG (Indonesia) (three times). Just seven of them deal with severe weather or early warnings (including earthquakes and tsunamis), and 15 times with some curiosities and 


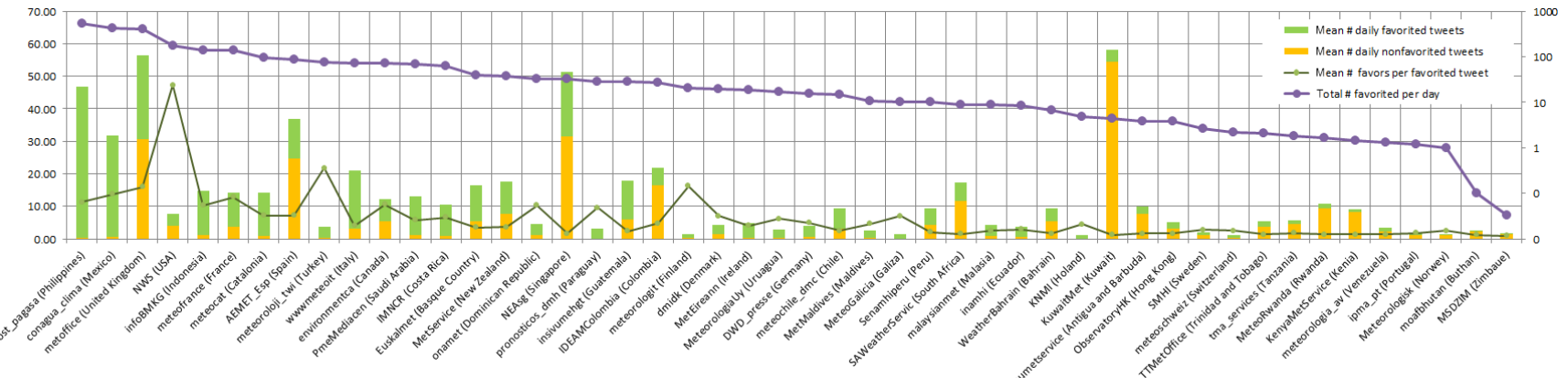

Figure 3. Favorited analysis showing (left) daily averaged values per day during 2016, ratio of favors per favorited tweet and proportion of favorited tweets and (right with logarithmic scale) number (\#) of total favorited.

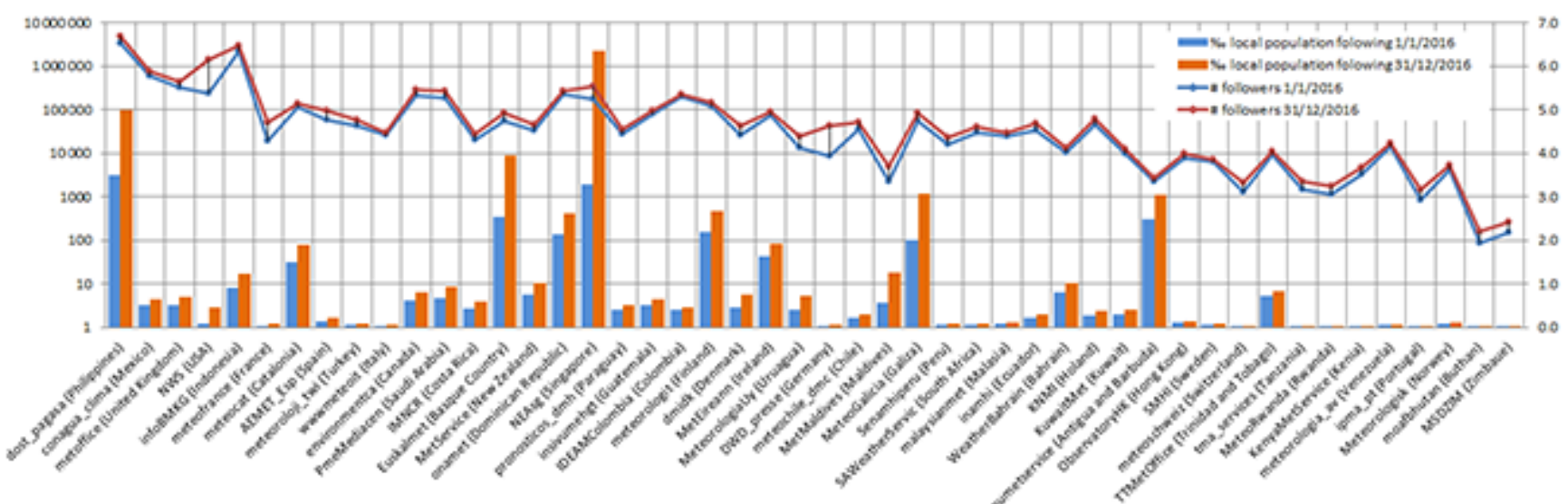

Figure 4. Followers analysis showing number (\#) of followers (left with logarithmic scale) and proportion of local population following (right) pre-2016 (blue) and at the end of 2016 (red).

general information. In nearly all the cases attached information is present.

\subsection{Followers}

Followers refers to anyone who has clicked the Twitter "follow" button to subscribe to another user's messages, simply someone who potentially can receive direct tweets and read them. Just three WS had more than 1000000 followers at the end of 2016: dost_pagasa (Philippines), infoBMKG (Indonesia) and NWS (USA). Top three WS with followers in proportion to local population following were NEAsg (Singapore) (6\%), dost_pagasa (Philippines) (5\%), and Euskalmet from the Basque country (4\% population following), with a mean monthly rate of new followers per 1000 inhabitants of 2.1, 1.1 and 1 respectively (see Figs. 1 and 4).

Note that NWS (USA), DWD_presse (Germany) and meteofrance (France) had an increase in followers during 2016 (compared to pre-2016) of $493 \%, 382 \%$ and $165 \%$ well above mean growing rate of $60 \%$ (Fig. 1).

\section{Remarks and conclusions}

The use of Twitter is relatively widespread among weather services all around the world (40\% have an active account)
(Gaztelumendi et al., 2015). The communication strategy, operational routines, information content and relationship with followers are very different depending on country and type of weather service.

Practices for providing content to messages are very diverse. Regarding the degree of human intervention, on one hand there are centers that work with a very high degree of automation by emitting posts with automatic observations at regular times. On the other hand many centers have a null degree of automation elaborating manually the contents. The text of the tweets is also varied. There are centers that use very formal language, while others avoid the technicalities and transmit the information in ordinary, non-formal language. In the case of information about severe weather, the centers that include it (for the most part) usually use formal language to transmit it.

Focusing on relationship with the community of followers, the practices also varied greatly. In regard to retweets, there are some centers that do not retweet anything from other users, while others have ratios greater than $50 \%$ retweets. In the case of replies, something similar happens. There are centers that never respond to users, while others have a high degree of interaction with them - in some cases with very high response rates. 
The degree of acceptance of each Twitter service is also heterogeneous. To analyze this aspect, we put the focus on followers and favorites. Favorites are difficult to analyze because they heavily depend on cultural aspects. For acceptance purposes it is interesting to consider the absolute follower numbers with potential audience. This is a complex task where we need to consider multiple aspects such as connected mobile phones availability, general Twitter usage ratios, beginning date of service, language, and general/local character of the particular WS among others. In any case, when we included the country inhabitants as a measure of potential users, we found that some Asian WS accounts and local European WS have the best ratios.

The average number of daily tweets increased by two in 2016, rising to 12.7 at the end of 2016 with a total volume of 1076000 tweets sent from the beginning of the different services, for a total volume of followers of 13311718 . Although some WS accounts activities differ a lot from others, those amounts can be considered representative in general. Nevertheless note that all combined were fall short of expresident of the United States Barack Obama, who had more than 100 million followers (with just 15500 tweets posted).

Attracting followers and maintaining them is a very complex task, considering that there is no direct relation between the number of tweets (effort) and the number of followers of an account (reward), even if the posts are non-automatic, interesting, and relevant.

Data availability. The data used in this work are not public. Contact the corresponding author if the data are required for research purposes.

Competing interests. The authors declare that they have no conflict of interest.

Special issue statement. This article is part of the special issue "17th EMS Annual Meeting: European Conference for Applied Meteorology and Climatology 2017'. It is a result of the EMS Annual Meeting: European Conference for Applied Meteorology and Climatology 2017, Dublin, Ireland, 4-8 September 2017.

Acknowledgements. The authors would like to thank the Emergencies and Meteorology Directorate - Security Department - Basque Government for operational service financial support, and all our colleagues from TECNALIA and EUSKALMET for their daily effort in promoting valuable services for the Basque community. We would also like to thank R Community and all institutions and people that maintain and support availability of free data and tools for the Scientific Community.

Edited by: Tanja Cegnar
Reviewed by: Panagiotis Giannopoulos, Tanja Cegnar, and one anonymous referee

\section{References}

Boyd, D., Golder, S., and Lotan, G. :Tweet, Tweet, Retweet: Conversational aspects of retweeting on Twitter, in: IEEE HICSS-43, 6 January 2010, Kauai, HI, 2010.

Gaztelumendi, S., Egaña, J., Otxoa de Alda, K., Hernandez, R., Aranda, J., and Anitua, P.: An overview of a regional meteorology warning system, Adv. Sci. Res., 8, 157-166, https://doi.org/10.5194/asr-8-157-2012, 2012.

Gaztelumendi, S., Orbe, I., Lopez, A., Aranda, J. A., and Anitua, P.: Social media and high impact weather communication in Basque Meteorology Agency, in: 13th EMS/11th ECAM, 9-13 September 2013, Reading, UK, 2013.

Gaztelumendi, S., Martija, M., Principe, O., and Palacio, V. :An overview of the use of Twitter in National Weather Services, Adv. Sci. Res., 12, 141-145, https://doi.org/10.5194/asr-12-141-2015, 2015.

Gaztelumendi, S., Orbe, I., Salazar, O., Lopez, A., Aranda, J. A., and Anitua, P.: Delivery and communication of severe weather events in Basque Country: the Euskalmet case, Adv. Sci. Res., 13, 87-90, https://doi.org/10.5194/asr-13-87-2016, 2016.

Gentry, J.: Package "twitteR", https://cran.r-project.org/web/ packages/twitteR/twitteR.pdf, last access: 29 August 2016.

Martija, M., Palacio, V., Príncipe, O., and Gaztelumendi, S.: Meteo adversa y su comunicación vía radio y Twitter, in: XXXIII Jornadas científicas de la AME, 7-9 April 2014, Oviedo, Spain, 2014.

Orbe, I.: Emergencias y medios de comunicación, Publicación de academia vasca de policía y emergencias, Arkaute Akademia, Araba, 2012.

Palacio, V., Martija, M., Príncipe, O., and Gaztelumendi, S.: Servicios meteorológicos y Twitter, in: XXXIII Jornadas de la AME, 7-9 April 2014, Oviedo, Spain, 2014.

Palacio, V., Principe, O., Martija, M., and Gaztelumendi, S.: An overview of the use of Facebook in National Weather Services, Adv. Sci. Res., 13, 145-150, https://doi.org/10.5194/asr-13-1452016, 2016.

R Core Team: R: A language and environment for statistical computing, R Foundation for Statistical Computing, Vienna, Austria, http://www.R-project.org/ (last access: 28 June 2017), 2014.

Sanchez, G.: Handling and Processing Strings in R, Trowchez Editions, Berkeley, 2013.

Smart Insights: Global social media research summary 2018, https://www.smartinsights.com/social-media-marketing/ social-media-strategy/new-global-social-media-research/, last access: 10 May 2018.

Tsukayama, H. : Twitter is officially doubling the character limit to 280, The Washington Post, https: //www.washingtonpost.com/news/the-switch/wp/2017/11/ 07/twitter-is-officially-doubling-the-character-limit-to-280/ ?utm_term=.11568d8745fa, last access: 7 November 2017.

WMO: National Services, https://public.wmo.int/en/about-us/ members/national-services, last access: 27 July 2017. 